\title{
Fragmentos de un discurso sofístico: Antifonte, entre Protágoras y Gorgias
}

\section{Fragments of a Sophistic Discourse: Antiphon, between Protagoras and Gorgias}

\author{
Julián Gallego ${ }^{1}$ \\ PEFSCEA/Universidad de Buenos Aires-CONICET \\ (Argentina)
}

Recibido: 17-09-19

Aprobado: 15-06-20

\section{Resumen}

El artículo analiza la producción sofística a partir del caso singular de Antifonte, en virtud del problema de su identidad. Se acepta que el orador y el sofista son la misma persona, lo cual altera la configuración del corpus que se les atribuye. Esto permite analizar conjuntamente las Tetralogías del orador y el Sobre la verdad del sofista. Siguiendo estos textos se aborda su pensamiento centrado en dos núcleos fundamentales: el lógos y el nómos, con los que la sofística elabora un pensamiento sobre la organización de la pólis. Las posiciones de Antifonte son cotejadas con las de Protágoras y Gorgias, para indicar sus puntos de vista en común.

Palabras-clave: Sofística, Antifonte, Lógos, Nómos, Verosimilitud, Convencionalidad.

\footnotetext{
${ }^{1}$ (julianalejandrogallego@gmail.com) Profesor Titular de Historia Antigua Clásica e Investigador Principal del CONICET. Se desempeña actualmente como Director del Instituto de Historia Antigua y Medieval, Facultad de Filosofía y Letras, Universidad de Buenos Aires. Es asimismo Miembro Colaborador del Laboratório de História Antiga, Universidade Federal do Rio de Janeiro, e Investigador Asociado del Institut des Sciences et Techniques de l'Antiquité, Université de FrancheComté, Besançon. Entre sus publicaciones se cuentan los libros La democracia en tiempos de tragedia (2003), El campesinado en la Grecia antigua (2009), La pólis griega (2017) y La anarquía de la democracia (2018), entre otros.

ORCID: https://orcid.org/0000-0002-3394-357X
}

Araucaria. Revista Iberoamericana de Filosofia, Política, Humanidades y Relaciones Internacionales, año $22, \mathrm{n}^{\circ} 44$. Segundo semestre de 2020. Pp. 249-270. ISSN 1575-6823 e-ISSN 2340-2199 https://dx.doi.org/10.12795/araucaria.2020.i44.11 


\begin{abstract}
The article analyzes the sophistic production from the singular case of Antiphon, by virtue of the problem of his identity. It is accepted that the orator and the sophist are the same person, which alters the configuration of the corpus attributed to both. This allows us to jointly examine the orator's Tetralogies and the On Truth by the sophist. Following these texts, his thinking focused on two fundamental cores is addressed: logos and nomos, with which sophistry elaborates a thinking on the organization of the polis. Antiphon's positions are compared with those of Protagoras and Gorgias, to indicate their points of view in common.
\end{abstract}

Key-words: Sophistry, Antiphon, Logos, Nomos, Verisimilitude, Conventionality.

\title{
Introducción
}

El análisis de la producción sofística entraña la dificultad que se deriva de un corpus tan fragmentario e indirecto. Por ello, se parte aquí de un efecto que se considera definitorio de la sofística, esto es, su capacidad de deconstrucción de los campos en los que interviene, trazando así una trayectoria propia conducente a los nuevos ejes que pone de relieve (cf. Romilly 1997: 103139). Lo que emerge a partir de esas intervenciones son fragmentos de un discurso sofístico, parafraseando a Barthes (1982: 14-16), visibles no solo en los núcleos desarticulados de la sofística que nos han llegado sino también en parte de la literatura griega de la segunda mitad del siglo V a.C., en la que se observan gestos y marcas inherentes a las problemáticas sofísticas. Justamente, gracias a las huellas que estas han dejado en la cultura de su época, es posible aprehender muchas de sus figuras argumentales, improntas significativas que permiten entender uno de los "modelos de racionalidad" que trata de definir la situación de la ciudad en el plano de las ideas y los comportamientos políticos (cf. Plácido 1997). En este contexto, Antifonte resulta ser un caso singular, en virtud del problema de la identidad que, según cómo se resuelva, altera la configuración del corpus que se le atribuye. En este artículo se ensayará un abordaje de su pensamiento centrado en dos aspectos fundamentales: el lógos y el nómos, nociones con las que la sofística elabora un pensamiento positivo sobre la singularidad característica de la organización de la pólis, asumiendo el carácter ficcional de las convenciones legales. 


\section{Las Tetralogías y el lugar de Antifonte en el corpus sofístico}

Si para la gran mayoría de los sofistas el problema del corpus estriba en su estado fragmentario, con Antifonte ocurriría algo que lo distingue y que consiste en su multiplicidad, o al menos en su duplicidad: habría un Antifonte orador y otro sofista. El primero se identifica con el ateniense que interviene en el golpe oligárquico de 411 a.C. y muere ajusticiado por la restauración democrática que tuvo lugar poco después, según Tucídides (8.68.1-2; 8.90.1$2)^{2}$. Para el caso del segundo se tienen, básicamente, los datos que brinda Jenofonte (Memorables, 1.6), siempre y cuando se asuma decididamente que el sofista es alguien diferente del orador.

Conforme a esta tradicional división, en el corpus del orador se incluyen seis discursos completos, entre ellos las tres Tetralogías, y algunos fragmentos, mientras que el sofista sería el autor de cuatro tratados conservados parcial e indirectamente, excepto Sobre la verdad, gracias a los papiros hallados a inicios del siglo XX. En ambos casos se ha discutido la posibilidad de que todos los textos fueran del mismo autor: el orador de las Tetralogías sería alguien distinto del de los otros discursos; el sofista no pudo sostener al mismo tiempo la igualdad natural radical quitando importancia a la ley positiva, como se verá en Sobre la verdad, y el rechazo de la anarquía elogiando la obediencia a los mandatos, como en Sobre la concordia (DK 87 B 61).

Solo como muestra de las dificultades que ha acarreado y sigue suscitando la separación y la atribución de las obras, cabe mencionar a Gernet (1923: 4-16, 172-175), que en su edición del orador Antifonte avalaba la existencia de dos autores, pero sostenía que el asunto era complejo porque en el corpus se transmiten discursos o restos y las Tetralogías, que no serían del Antifonte "real" (sic) sino del sofista, una alternativa que también Nestle (1961: 139141) creía factible: las Tetralogías y los fragmentos sofísticos serían del sofista, mientras que los demás discursos, los fragmentos de oratoria y Sobre la concordia serían del orador. Uno de los argumentos esgrimidos para separarlos ha sido el estilo; pero Hermógenes (Sobre las formas oratorias, 2.11.7 = DK 87 A 2) ya advertía que las diferencias estilísticas bien podían responder a los diversos géneros literarios abordados, aunque él mismo, sin dejar de lado las dudas, optaba por separar al orador y el sofista ${ }^{3}$. Siguiendo diversas referencias, Lesky (1968: 382-383) comprobaba una variada actividad que avalaría la idea de que se trata del mismo personaje bajo múltiples facetas; no obstante, decidió seguir el criterio de Nestle que planteaba la imposibilidad de que quien fuera uno de los líderes de la revuelta oligárquica de 411 pudiera haber manifestado

${ }^{2}$ Cf. también Aristófanes, Avispas, 1269-1270, 1301-1302; Platón, Menéxeno, 236a; [Aristóteles], Constitución de los atenienses, 32.2. Ver Gallego 2018a: 48-49, con más referencias y bibliografía.

${ }^{3}$ El comentario de Hermógenes parece depender de la obra del gramático Dídimo de Alejandría. 
al mismo tiempo las ideas sobre la igualdad natural de todos los hombres que se leen en Sobre la verdad; el equívoco subsistía, pero Lesky optaba por duplicar a Antifonte.

El problema, que Untersteiner (1949: 274-278) creía resuelto a partir de la intervención de Bignone (1919a; 1919b = 1974: 7-20, 21-57), fue sin embargo reabierto por Morrison (1961) avalando la hipótesis de la identidad, rápidamente criticado por Luria (1963) en favor de la idea de la duplicidad, perspectivas que Guthrie (1971: 285-286, 292-294), siguiendo a Bignone, sintetiza adecuadamente brindando referencias adicionales. Varios trabajos recientes han vuelto sobre el asunto. Al ocuparse del rol de Antifonte en el golpe oligárquico de los Cuatrocientos, Ostwald (1986: 359-364) plantea el asunto de la identidad y señala que si bien las pruebas no son concluyentes es probable que tanto las Tetralogías como los discursos realmente pronunciados y el Sobre la verdad fueran del mismo autor. Cole (1991: 100) aduce de forma sumaria que puede o no ser el mismo autor; pero su tratamiento de las obras parece llevar a la idea de que no hay desdoblamiento, en la medida en que el análisis de las Tetralogías junto con las demás obras retóricas deja ver que no hay diferencias sustanciales que lleven a separarlos. Grimaldi (1996: 33-34) declara que muy posiblemente hubo un Antifonte, no dos. La polémica se ha reavivado a partir de las posiciones de Gagarin (2002: 38-52), a favor de la unicidad -planteada ya en un trabajo previo (Gagarin 1990)-, y de Pendrick (2002: 1-26), a favor de la duplicidad -también adelantada anteriormente (Pendrick 1987) ${ }^{4}$. En mi opinión, la reconsideración de Cassin (1995: 154-161) sigue siendo la más sugerente, quien examina el conjunto de cuestiones y afirma la identidad de Antifonte, orador y sofista. La autora hace de este problema una prueba del propio estatuto de la sofística: el personaje es en sí mismo un paradigma de la impugnación sofística de la identidad, puesto que existe un paralelo entre las perspectivas contradictorias de la sofística y los juicios también contradictorios que se han sostenido sobre Antifonte. En consonancia con la reformulación de Cassin, aquí se considera bajo el nombre único de Antifonte el conjunto de las producciones discursivas del orador y el sofista. Así, asumir la unidad de Antifonte, orador y sofista, trae derivaciones de peso para la conformación del corpus, en el que coexisten tratados como Sobre la verdad y ejercicios de escuela como las Tetralogías, así como para el pensamiento sofístico en general, poniendo de relieve a un tiempo su preocupación por la capacidad performativa del lógos y la autoridad convencional del nómos.

\footnotetext{
4 Bonazzi 2004a revisa ambas posturas. Que Jenofonte, Memorables, 1.6.1, hable del sofista Antifonte puede ser un indicio no de separación respecto de un Antifonte orador, sino de calificación peyorativa por parte de Jenofonte en función de diferenciar y elevar la figura socrática.

${ }_{5}$ Cf. Avery 1982; Gagarin 1990. Por mi parte, también he considerado los aportes de Plácido 1989 y Palerm 1996.
}

Araucaria. Revista Iberoamericana de Filosofia, Política, Humanidades y Relaciones Internacionales, año $22, \mathrm{n}^{\circ} 44$. Segundo semestre de 2020. Pp. 249-270. ISSN 1575-6823 e-ISSN 2340-2199 https://dx.doi.org/10.12795/araucaria.2020.i44.11 
Pero, ¿a qué se debe aquí el interés en esta polémica en torno a la identidad? Las marcas sofísticas presentes en los textos llevan a pensar en un deliberado trabajo sobre los enunciados conforme a las circunstancias, de modo que las diferencias de estilo que se puede hallar entre unos escritos y otros no obedecen a diferentes identidades sino a una identidad nominal que se disuelve en una enunciación discursiva múltiple. Lejos de pensar en una soberanía lineal y permanente del autor como alguien siempre idéntico a sí mismo, se debe pensar que dicha identidad nominal es un factor que la dinámica creadora del discurso no tiene por qué tomar en cuenta, máxime cuando se está hablando de un intelectual que asume en plenitud las radicales consecuencias derivadas de las intervenciones sofísticas en torno al problema del estatuto performativo y el funcionamiento persuasivo del lenguaje. Como argumenta Cassin (1995: 164):

Es pues por sólidas razones teóricas, ligadas a la sofística como impulso de lo político y a la especificación de lo convencional y lo legal como lógico o del lenguaje, que un mismo Antifonte es susceptible de ser percibido, por un lado, como orador y sofista y, por el otro, como oligarca y demócrata, sin que se tenga que buscar en la historia la coartada de un desdoblamiento.

En consecuencia, las Tetralogías son parte integrante de un corpus que se convierte en uno de los repertorios más importantes y se caracteriza por una impronta sofística evidente que, a pesar de duplicar a Antifonte, Hermógenes no pudo más que reconocer a partir de sus estilos sophisteúsantes. Pero aun si las Tetralogías son composiciones metodológicas de retórica judicial cuyo modelo no es un reflejo de la oratoria en público, no obstante, este cuasi-género posee una estructura tramada como una sucesión de cuatro discursos que tienen como referencia las prácticas típicas de los tribunales ${ }^{6}$ : acusación y defensa, duplicándolas con una nueva acusación y defensa, cada una tomando en cuenta los argumentos previos. Se trata de una contraposición entre cuatro discursos que interpretan y ordenan cuatro veces los mismos "hechos", entre comillas porque se trata de la verosimilitud de los mismos, como se indica en la Tetralogía I:

\begin{abstract}
Aun cuando se esfuerzan en probar mediante indicios de probabilidad (eikóton) que soy culpable, afirman que yo soy el asesino de este ciudadano no de acuerdo con la verosimilitud, sino con la realidad (ouk eikótos all'óntos). Ahora bien, ya ha sido cumplidamente demostrado que los demás indicios de probabilidad (eikóta) están en mayor medida a mi favor (2.4.10).
\end{abstract}

\footnotetext{
${ }^{6}$ Este uso contradictorio de la misma situación por dos partes que se enfrentan en el litigio no es privativo de la sofística, sino que también se verifica en la retórica desde su conformación; en todo caso, ambas remiten a una condición propia de la democracia. Cf. Plácido 1973: 66; Desbordes 1996: 44-54. Para una visión de conjunto de los comienzos de la retórica y su relación con la sofística, con referencias a Córax y Tisias como iniciadores de la retórica, ver Kennedy 1994: 11-29; Yunis 1998; Schiappa 1999: 3-29, 34-47. Sobre ambos rétores, Platón, Fedro, 273a-c; Aristóteles, Retórica, 1402a 16-23; con los análisis de Gagarin 1994: 48-51, y Grimaldi 1996: 21-22.
} 


\section{O como manifiesta claramente Antifonte en la Tetralogía II:}

Los litigantes... nos imaginamos estar dirigiéndonos, unos y otros, discursos verosímilmente (eikótos) justos; a vosotros [los supuestos jueces], digo, os corresponde considerar los hechos (tà prakhthénta) de un modo piadoso. Porque la verdad (alétheia) de estos debe ser examinada a partir de cuanto se está diciendo (legoménon)" (3.4.2; cf. Tetralogía I, 2.4.1).

El problema es indicado por Gorgias (Defensa de Palamedes, $35=$ DK 82 B 11a) -cuya posible influencia sobre Antifonte se produciría a partir de su paso por Atenas en $427^{7}$-, al decir que sería fácil la decisión si solo se la tomara a partir de los dichos, porque mediante las palabras la verdad de los hechos sería evidente para los oyentes, aunque esto no sea $\operatorname{asi}^{8}$. Cassin (1995: 174) propone cuál es el campo de asignación de esta verdad: hechos, actos y cosas, que son otros tantos elementos que se debe establecer; por eso, dicha verdad jamás sobrepasa el fuero interno9. En rigor, solo se puede juzgar la responsabilidad de los actos mediante la interpretación de los hechos según los argumentos discursivos siguiendo la lógica de lo verosímil.

Esto es lo que Antifonte lleva hasta las últimas consecuencias lógicas en la Tetralogía I dando un lugar fundamental a la argumentación cimentada en lo verosímil o probable (eikós) y la construcción de razonamientos verosímiles (eikóta) que se enfrentan pretendiendo ser unos más verosímiles (eikótera) que otros ${ }^{10}$ : la acusación asevera que verosímilmente (eikótos) el acusado lo premeditó, por lo que verosímilmente también lo mató para defenderse de sus ataques (2.1.6); según el acusado es aún más verosímil (eikóteron) que él hubiera previsto que iba a ser verosímil que fuera tenido por sospechoso (2.2.3). Todo esto se organiza como una comparación entre dos argumentos igualmente probables circunscripta al momento preciso de la disputa, que se convierte en el criterio para evaluar: la lógica de lo verosímil, que ante una probabilidad se pueda contraponer otra; este segundo principio resulta más fuerte que el primero porque conlleva una decisión entre dos posibilidades. El tercer principio supone una lógica de la inversión que se desprende del anterior; se trata en rigor de un mecanismo perpetuo (cf. $2.3 .7 ; 2.3 .9 ; 2.4 .10 ; 2.2 .4$ ): es

\footnotetext{
${ }^{7}$ Sobre la embajada de Gorgias en Atenas, cf. Williams 1931; Enos 1992.

${ }^{8}$ Gagarin 2002: 126 y n. 57 (119-127: el autor hace girar todo el análisis de la Tetralogía II en torno a este eje), plantea un contraste profundo entre Antifonte y Gorgias en torno a esta cuestión; no obstante, ambos autores parecen apelar a la verdad de los hechos desde el discurso que los relata y, por ende, el régimen argumental que los hace verosímiles. Ver Gorgias, Encomio a Helena (DK 82 B 11), 1-2, 13, 16, y Defensa de Palamedes (DK 82 B 11a), 4-5, 24, 33, 35, donde las apelaciones a la verdad solo dependen de los dichos sobre los hechos, es decir que la verdad se predica de un discurso, pero no por su adecuación a los hechos, sino por el peso de los argumentos.

${ }^{9}$ Cf. Antifonte, Tetralogía I, 1.1.6; Sobre el asesinato de Herodes, 5.87 y 93.

${ }_{10}$ Sobre el trabajo sobre lo verosímil, con especial énfasis en los desarrollos producidos por Antifonte, ver Gagarin 1994: 52-53, 55-56, 62-64, y, más específicamente, Gagarin 2002: 112-118; cf. López Eire 1994: 47-48, 61.
} 
verosímil que alguien haya previsto un homicidio y por eso es culpable, señala la acusación; es incluso más verosímil que alguien previera que sería verosímil que él había previsto el crimen y, por lo tanto, es inocente, argumenta la defensa; y un paso más: puede resultar aún más verosímil que alguien previera que sería más verosímil que él hubiera previsto que resultaría verosímil que él había previsto el crimen, puede decir la acusación en su segunda intervención; siguiendo siempre el criterio esbozado, la defensa puede dar el último paso. Y es posible argumentar de igual manera, pero en sentido contrario: el criterio de lo menos verosímil. El enunciado verbal que comanda esta ley es la premeditación o previsión (epiboulé); la cadena perpetua de verosimilitudes que se refutan y se invierten conduce a que lo verosímil solo implique lo verosímil, un régimen de verdad en el que los hechos solo son a partir de los dichos ${ }^{11}$.

Estos discursos están organizados por procedimientos sofísticos, en particular, los dos argumentos contrapuestos (dýo lógoi antikeímenoi) postulados por Protágoras, quien señalaba la posibilidad de sostener al mismo tiempo un discurso y su contrario (Diógenes Laercio, 9.51 = DK 80 A 1; DK 80 B 6a; cf. DK 80 A 20). Existe, pues, una lógica de la ambigüedad inherente a lo verosímil y los discursos contradictorios, que supondría asimismo la ocasión apropiada ${ }^{12}$. Al igual que Gorgias en Sobre el no-ser (DK 82 B 3 y 3bis) -que será analizado luego con más detalle- y Protágoras en la apología del Teeteto de Platón (166d-167c), Antifonte parece indicar en sus Tetralogías que no hay modo lógico de acceder a la verdad, si se entiende como adecuación entre la palabra y la cosa, es decir, un discurso que conmemora o representa un mundo que se encuentra fuera de él. En el caso del sofista de Leontinos, una de las formas de demostrar que nada existe radica en afirmar la singularidad del lógos que solo comunica lo que él mismo es, con tal fuerza que es capaz de producir efectos sobre los cuerpos. No hay, así, criterio posible de verdad. En cuanto a Protágoras, si bien el punto de partida es el opuesto, por cuanto para él las percepciones de cada uno son verdaderas, que se pueda sostener juicios contrarios sobre lo mismo, que se pueda confrontar las representaciones para determinar si son mejores o no y que se llegue, en definitiva, a una inversión de los puntos de vista de los hombres a través del argumento más fuerte (lógos kreitton) en función del interés general de la pólis, todo esto conduce al poder persuasivo del lógos, su naturaleza contradictoria y su capacidad comunicativa en virtud de la cual es posible una fabricación retórica de la verdad, que no es otra cosa que la convención en la que se sostiene el lazo

${ }^{11}$ Cf. Cassin 1995: 171-175 (cf. 155, 163), que realiza un análisis exhaustivo de estas marcas de enunciación.

${ }^{12}$ Un elemento esencial que entraña la lógica ligada a lo eikós es el kairós, la circunstancia singular, que Antifonte pone de relieve en la Tetralogía II (3.3.6), aunque no parece otorgarle demasiado peso. Gorgias señala a este factor como una condición importante de la enunciación retórica: DK 82 A 1a y 24 (a partir de Filóstrato, Vida de sofistas); cf. Defensa de Palamedes (DK 82 B 11a), 28. Sobre la cuestión, Tortora 1985; Chialva et al. 2013: 37 y n. 23. El kairós también es factor relevante en Protágoras; al respecto, ver Solana Dueso 2000: 21-30.

Araucaria. Revista Iberoamericana de Filosofia, Política, Humanidades y Relaciones Internacionales, año $22, \mathrm{n}^{\circ} 44$. Segundo semestre de 2020. Pp. 249-270. ISSN 1575-6823 e-ISSN 2340-2199 https://dx.doi.org/10.12795/araucaria.2020.i44.11 
social comunitario como una experiencia con sentido.

Sobre la base de las antilogías (Gagarin 2002: 22-31, 100-104, 133), Antifonte produce un discurso con características específicas asociado con la práctica de los tribunales en el que la lógica de lo verosímil, los argumentos en pro o en contra con arreglo a la interpretación de los mismos hechos y los discursos dobles constantemente enfrentados muestran que los hechos no son una garantía de verdad para los dichos sino más bien lo contrario: son efectos de esos dichos, una producción discursiva que hace ser; el discurso que se impone en la contraposición remite al poder persuasivo del lógos kreítton que recibe las adhesiones mayoritarias. Entonces, la palabra hace ser, produce un efecto de realidad; el modo de fabricación de la verosimilitud es el de la apáte $^{13}$, que se suele definir como engaño pero que mejor sería pensar como estratagema o artificio, ideas más cercanas a la de ficción sobre la que se retornará ulteriormente. Esta es la forma de construcción de la verdad según el régimen discursivo sofístico, ya no como alétheia sino en tanto que dóxa ligada a lo eikós: no se trata ni de una auto-representación de la verdad y sus límites mediante el lógos, ni de adecuación de la palabra con el mundo, sino de producción de una verdad por un discurso que asume su capacidad de hacer ser, cuya fuerza consiste en una materialidad que actúa sobre los cuerpos. La alétheia no interesa como hecho en sí, inmutable, absoluto y esencial; importa la verosimilitud de un discurso que, con sus márgenes múltiples, es capaz de abrir un campo para la opinión, es decir que adquiere su estatuto de verdad a partir de la inconsistencia y la incertidumbre y en virtud del convencimiento y la decisión ${ }^{14}$.

\section{Sobre la verdad, o la convencionalidad de la política}

Lo desarrollado en el apartado previo permite inducir una significativa articulación entre las ideas de Antifonte y los aportes de Protágoras y Gorgias, de quienes aquel fue prácticamente coetáneo. Claro está, esta coincidencia no se agota en el hecho anecdótico de la contemporaneidad, sino que remite a los acoplamientos conceptuales entre aspectos troncales de sus pensamientos. No parece extemporáneo, pues, que para delimitar en qué sentido el Sobre la verdad

13 Detienne 1981: 126: “[Existe] una zona específica de lo ambiguo, un plano de lo real que pertenece al orden exclusivo de la apáte, de la dóxa, de lo 'alethés y de lo pseudés"'. Este campo deja afuera la alétheia y se constituye como otro sistema de pensamiento en el que "lo ambiguo ha dejado de ser la unión de los contrarios complementarios, para convertirse en la síntesis de los contrarios 'contradictorios"'

14 Sobre los aspectos reseñados, Gorgias, Encomio a Helena, $11=$ DK 82 B 11; Aristóteles, Retórica, 1402a 21-28 = Protágoras, DK 80 A 21; Gomperz 1951: I, 522-526; Untersteiner 1949 : 66-75; Plácido 1973: 58-62. 
de Antifonte ${ }^{15}$ establece el carácter convencional de la política se empiece por el mito de Protágoras, donde se sugieren los efectos decisivos del advenimiento de la pólis, que ha de incluir a todos los hombres sin excepción ya que de otro modo ella no podría existir. La adquisición humana del arte político se asocia con la distribución entre todos los hombres del respeto (aidós) y la justicia $(\text { dike })^{16}$, lo cual se puede considerar como el surgimiento de una configuración política en la que aidós y dike -que no tienen otro objeto que el hecho de mostrar respeto y justicia- actúan en la inmanencia de la situación como principios ordenadores y creadores de lazos de amistad, manteniendo a los hombres unidos en la pólis (Protágoras, 320c-322d). El enunciado protagoreo propone que la virtud política va de la mano con la justicia y que la comunidad debe compartir la idea de que todos los hombres son justos; a la vez, más allá de que efectivamente lo sean, estos deben sostener esa significación básica como margen de la situación política, para poder así quedar incluidos en ese acuerdo que es básicamente una democracia ${ }^{17}$, a la manera de lo que modernamente se designa con la noción de lazo social imaginario. Una vez instituida la política como práctica humana distintiva, Protágoras considera no solo que la virtud es enseñable, sino que, además, se sostiene sobre una ficción que permite la existencia de la pólis: no se trata de ser esencialmente justo sino de actuar como si se fuera justo según las normas vigentes. Así, el respeto y la justicia son en realidad el acuerdo que prestan tácitamente todos los que participan de la virtud al quedar incluidos en esa convención política, aceptando que todos los hombres son capaces de mostrar aidós y dike (322e-323a, 327d) ${ }^{18}$.

Para comprender cabalmente estos términos y precisar qué relación guardan con el carácter ficcional del acuerdo establecido es necesario dirigirse a las puntualizaciones de Antifonte (cf. Romilly 1997: 119-137): "La justicia (dikaiosýne) consiste en no transgredir (mè parabaínein) el conjunto de leyes (tà pánta nómima) de la ciudad en la que se participa como ciudadano (politeúetaí tis)" (Sobre la verdad, fr. 1 A, col. I = DK 87 B 44) ${ }^{19}$. En su radicalidad, esta

15 Respecto de este tratado, ver los fundamentados análisis de Cassin 1995: 171-175, Gagarin 2002: 63-92, y Pendrick 2002: 32-38, 246-377, sobre los cuales volveremos recurrentemente a lo largo de estas páginas.

16 Hay diversas exégesis de estos términos, en particular de aidós. Cf. Mondolfo 1955: $536 \mathrm{n}$. 5; Guthrie 1971: 66; Cairns 1993: passim, y 354-360, para Protágoras; Beresford 2013: 156-158; Manuwald 2013: 164-169, 171-175. Para Zilioli 2007: 96 y n. 20-21, aidós implica "respeto", por uno mismo y los demás, sin necesidad de aclararlo.

${ }^{17} \mathrm{La}$ asociación del pensamiento de Protágoras con la democracia es casi un locus communis; cf. Gallego 2000 (= Gallego 2003: 347-372), y Gallego 2016 (= Gallego 2018b: 73-90). Contra Saxonhouse 2006: 179-205; cf. Monoson 2000. Para Bonazzi 2004b, que sigue posturas previas, Protágoras produce la primera teoría de la democracia en el contexto cultural de la Atenas de la época de Pericles, a lo cual se opondría Platón, precisamente.

${ }^{18}$ Cf. Sørensen 2016: 100-132, y esp. 118 y 122: a partir de comportamientos, valores y prácticas que ella misma acepta, cada comunidad desarrolla un consenso que encuadra las experiencias individuales de sus ciudadanos.

19 Ver las versiones del Sobre la verdad de Cassin 1995: 273-278 (solo los fragmentos I-III), y 
definición es la expresión más acabada del carácter convencional de la política, con consecuencias para otros campos del pensamiento sofístico, empezando por la tesis protagorea: "El hombre es la medida de todas las cosas, de las que son en cuanto son, de las que no son en cuanto no son" ${ }^{20}$. Es un tópico en las discusiones avezadas privilegiar tres grandes ejes interpretativos: el subjetivista, el objetivista o el convencionalista. Puesto que los dos primeros se centran en el carácter individual o genérico del hombre, en su particularidad o en su generalidad más absolutas ${ }^{21}$, respectivamente, apuntado a distintos planos de la naturaleza humana sin inscripción histórica alguna, parece más activa la perspectiva convencionalista de la tesis, en la que "hombre" designa a un emergente modélico de una sociedad singular históricamente determinada, es decir, una colectividad asentada en la misma ley convencional que organiza el respeto y la justicia. En términos políticos, esta resulta ser la interpretación más eficaz de la tesis, pues pone el acento en un relativismo de orden práctico que jerarquiza la acción humana. Esto justifica que se entienda al hombre en un sentido colectivo, es decir, ni ser individual ni ser genérico, porque hace del mismo y de su actividad los principios del mundo y la sociedad. En este punto preciso el principio del hombre como medida de lo que es y de lo que no es se conecta con la idea protagorea de que todos los hombres han de participar de la virtud política o no existirían las ciudades (Protágoras, 322d: ou gàr àn génointo póleis; 323a: è mè eînai póleis) (cf. Bartlett 2016: 28-39). El enlace lo opera la función discursiva del lógos (Teeteto, 166d-167c), en la medida en que el criterio para establecer lo que es o lo que no es no queda ligado a la verdad o la falsedad sino a las representaciones imaginarias, que una sociedad tendrá por adecuadas mientras mantenga la convención que así las considera, puesto que, según la afirmación de Protágoras: "Lo que a cada ciudad le parezca (dokêi) justo y bueno, esto es (eînai) para ella en tanto que crea (nomíze) en eso" (167c). La virtud política consiste entonces en que los hombres participen activamente de las decisiones que la pólis establece y que, mientras se las juzgue pertinentes, rijan como leyes que hacen que cobren existencia o no para esos mismos hombres tales o cuales pautas y formas de conductas.

Este convencionalismo sociológico se puede sostener de forma plena en estos términos siempre y cuando se acepte la tesis de Antifonte, que conlleva una fabricación de lo legal de acuerdo con la operatoria discursiva del lógos.

Pendrick 2002: 102-191 (texto griego y traducción de los 44 fragmentos conservados); cf. Bertrand 1999: 298-303.

${ }^{20}$ Protágoras, DK 80 B 1, ap. Sexto Empírico, Contra los matemáticos, 7.60; cf. Platón, Teeteto, 152a, 166c-d; Crátilo, 386a. Para el análisis de las evidencias y las interpretaciones modernas, ver Gallego 2003: 360-369. Platón, Leyes, 716c, no se privará de dar una respuesta acabada contra Protágoras: "Dios, en verdad, ha de ser la mejor medida de todas las cosas para nosotros, y mucho mejor que el hombre, como por allí alguien dice".

${ }^{21}$ Cf. Platón, Teeteto, 152a-c, y Sexto Empírico, Esbozos pirronianos, 1.218 = DK 80 A 14, respectivamente.

Araucaria. Revista Iberoamericana de Filosofía, Política, Humanidades y Relaciones Internacionales, año $22, \mathrm{n}^{\circ} 44$. Segundo semestre de 2020. Pp. 249-270. ISSN 1575-6823 e-ISSN 2340-2199 https://dx.doi.org/10.12795/araucaria.2020.i44.11 
Si no existe definición de una esencia humana absoluta, universal e inalterable, si en Protágoras la naturaleza del género humano queda sometida al carácter relativo, singular y mutable de la convención, entonces el hombre como medida es el ciudadano que respeta la justicia según la ley de la ciudad de la que forma parte. Esto es lo que permite trazar la relación entre la virtud política como algo enseñable y el hombre como medida de lo que es: ser es ser políticamente para una pólis. El homo-mensura es el ciudadano según su especificidad a partir de su derecho concreto de ciudadanía. En política, pues, prima la contingencia: se es según la ley de una ciudad, según su singularidad normativa; se trata no solo de enunciar la exigencia de un convencionalismo sociológico sino también de asumir radicalmente esta tesis en función de la singularidad de las prácticas políticas de cada comunidad.

El punto de partida de Antifonte es, pues, el ser político del hombre conforme a la ley. No obstante, su discurso da un lugar expreso a la naturaleza, hecho que parece contradecir la extendida idea de que los sofistas dejan de lado la phýsis para ocuparse del nómos; también en este plano el sofista argumenta con extrema radicalidad. La primera consecuencia que extrae Antifonte de la tesis propuesta (Sobre la verdad, fr. 1 A, col. I) es que cualquier hombre hace uso de la justicia en total acuerdo con sus intereses (heautô xymphróntos) si ante testigos observa las leyes de la ciudad (toùs nómous megálous), pero si solo y sin testigos acata las de la naturaleza (tà tês phýseos). No transgredir la justicia según la ley implica situarse en el espacio público comunitario. Fuera de este solo se actúa según la justicia si se respeta lo que la naturaleza impone. En el paso distributivo del ser político colectivo al caso individual, lo más útil para un hombre ante los demás, los testigos, es observar plenamente las leyes de la pólis; pero considerar al hombre aislado de todo y de todos permite delimitar hasta dónde funcionan las pautas de la convencionalidad. Una vez sin testigos, lo conveniente para un hombre es obedecer las normas de la naturaleza: el hombre, entonces, en público es un ser político; en privado, un ser natural. ¿Es Antifonte un adepto al naturalismo ${ }^{22}$ ? Es menester destacar que la naturaleza solo aparece en un segundo momento en la formulación del sofista. De entrada, su enumeración incluye la justicia, las leyes, la ciudad y la participación como ciudadano; este es el contexto en el que cada individuo se vincula con sus semejantes, pero supeditados todos a las pautas políticas. El hombre absolutamente solo, sin público y en privado aparece luego, y es recién entonces cuando se mencionan las leyes naturales. En el discurso de Antifonte, la naturaleza aparece en segundo lugar; como veremos, esto implica que la ley solo se asienta en el consentimiento de los que participan del acuerdo, sin nada

${ }^{22}$ Para diferentes análisis de la relación entre nómos y phýsis y la postura política de Antifonte, ver Ostwald 1990; Donda, Reynoso y Rufinetti 1994; Bieda 2008; Corrales Cordón 2010; Levystone 2014.

Araucaria. Revista Iberoamericana de Filosofia, Politica, Humanidades y Relaciones Internacionales, año $22, \mathrm{n}^{\circ} 44$. Segundo semestre de 2020. Pp. 249-270. ISSN 1575-6823 e-ISSN 2340-2199 https://dx.doi.org/10.12795/araucaria.2020.i44.11 
que la trascienda y actúe como fundamento ${ }^{23}$.

Las derivaciones de este desplazamiento del nómos a la phýsis son tanto o más radicales que la tesis misma. Para Antifonte las exigencias de las leyes son accidentales, puesto que los preceptos legales son productos de las convenciones, no nacen por sí mismos. En cambio, las prescripciones de la naturaleza revisten un carácter necesario: se producen espontáneamente, no son el resultado de acuerdo alguno (fr. 1 A, col. I). La ley aparece entonces como contra natura, pero enunciada siempre en primer lugar. Evidentemente, el sofista no puede encontrar el estado natural pleno que se corresponda con la vigencia sin trabas de las leyes naturales. Si conforme a lo que es conveniente, los ojos ven o no, los oídos oyen o no, la lengua dice o no, las manos hacen o no, los pies conducen a un lugar o no, el espíritu desea o no, todo esto obedece a las codificaciones de las leyes (col. II-III). El afuera de las mismas radica en la naturaleza, pero esta no es una exterioridad salvaje respecto de las leyes, como la misantropía señalada en Protágoras (327d), sino un afuera interiorizado en la esfera de lo privado. La naturaleza es el secreto de lo privado, dice Cassin (1995: 168-170): primero se es ciudadano, que puede actuar pública o privadamente; en el espacio público, lo mejor es respetar la ley; en la vida privada, la naturaleza. Es entonces y solo entonces que puede aparecer la condición natural del hombre: "la naturaleza nunca es más que la escapatoria del secreto al imperio de lo político".

Pero, ¿qué ocurre cuando alguien transgrede las leyes? Va de suyo que el problema debe ser planteado en torno a las dos esferas que el sofista ha delimitado. Si las normas comunitarias se transgreden sin testigos, es decir, sin la presencia de todos cuantos participan de la convención, no existe entonces vergüenza alguna ni castigo a aplicarse; pero si alguien es descubierto, ocurre todo lo contrario. En cambio, si se hace violencia más allá de lo posible a "algún principio connatural a la naturaleza misma, aunque escape al conocimiento de toda la humanidad, el mal no es por ello nada menor; ni sería mayor en caso de que todos fueran testigos. Porque el daño resultante no lo determina la opinión (dóxa), sino la verdad (alétheia)" (fr. 1 A, col. II). La opción es evidente: naturaleza y verdad están en el mismo plano. Pero, por eso mismo, al igual que la naturaleza, la verdad es siempre segunda. En el terreno de la opinión, que es el del acuerdo, importa más no ser visto que no transgredir o, dicho de otro

23 Romilly 1971: 83-84, señala que Antifonte no estaba dando consejos, puesto que resulta necesario trazar una diferencia entre una dialéctica conceptual y un orador práctico; Antifonte debe ser ubicado en el primer campo, donde su análisis permanece inatacable, y si bien podían extraerse ciertas consecuencias prácticas, nada indica que así lo haya hecho. Lévy 1976: 98-89, contesta a lo afirmado por Romilly y argumenta que, dado que la concepción subversiva de Antifonte implica una depreciación de la ley, sería extraño que el sofista no sacara las derivaciones prácticas de sus propias posiciones; al limitar el campo de aplicación de la ley, lo que en rigor hace es describir cómo actúa la gente, encontrando así la razón de la conducta real de los hombres.

Araucaria. Revista Iberoamericana de Filosofia, Política, Humanidades y Relaciones Internacionales, año $22, \mathrm{n}^{\circ} 44$. Segundo semestre de 2020. Pp. 249-270. ISSN 1575-6823 e-ISSN 2340-2199 https://dx.doi.org/10.12795/araucaria.2020.i44.11 
modo, conviene decir lo oportuno, no el hecho en sí. Algo similar se deduce del ejemplo que da Protágoras tras la narración del mito: es más conveniente sostener el criterio legal y decir que se es justo, a pesar de ser y saberse injusto, que asumir el hecho en sí y declarar la propia injusticia ante testigos ${ }^{24}$.

Son significativas las derivaciones que se obtienen al poner en correlación la visión de Protágoras y el Sobre la verdad de Antifonte. Según el argumento del sofista de Abdera, alguien es injusto si se comporta como tal respecto de normas que son convencionales; pero si ello es desconocido por sus conciudadanos, ningún castigo ni vergüenza alguna caen sobre él. Si enuncia en público que es injusto entonces es culpable por transgredir ante testigos las reglas de la comunidad; pero habrá dicho la verdad, no una opinión. La reflexión de Protágoras apunta en la misma dirección que la de Antifonte: quien siendo injusto dice esa verdad pasa por loco y, como tal, debe ser excluido de la comunidad; la comparación es significativa: sería un misántropo similar a los que componían el coro de salvajes de una comedia de Ferécrates (Protágoras, 327d). Si la pólis se constituye a partir del supuesto de la participación de todos en la virtud política, que consiste en mostrar respeto y justicia, ser injusto y decirlo implica colocarse afuera de la situación. La educación, los tribunales, las leyes o cualquier otra coacción, señala Protágoras, deben actuar como constricciones sobre los hombres para obligarlos constantemente a preocuparse por la virtud, para no devenir en una especie de salvajes. Así, el mundo de la pólis resulta un efecto del lógos, la palabra que produce que advenga la situación política al mismo tiempo que prescribe lo enunciable y lo decible, de manera que bajo su ley hay discursos inexpresables. Decir la verdad es algo propio de la esfera privada, no de la pública; por lo tanto, no se puede decir y se debe conservar en secreto (cf. Untersteiner 1949: 300-314). Así concebida, la verdad es aquello de lo cual no se escapa y sobre lo cual no puede haber acuerdo político o convención. En consecuencia, la naturaleza no se despliega, ni se descubre ni es aquello en lo que se está inmerso originariamente, sino que es lo que queda en el vacío de lo político.

Antifonte coincide con Protágoras a partir de la proposición de que la alétheia ligada a la naturaleza no puede advenir en el campo político, que es un asunto de nómos y de dóxa. La naturaleza se revela en la esfera privada en la que impera la alétheia; pero como esto ocurre sin testigos, entonces no hay posibilidad de comunicarla; y ante testigos no se comunica la verdad, sino una opinión, que es la forma propia de lo verosímil que la convención requiere. Todo esto conduce a las tres tesis de Gorgias en el tratado Sobre el no-ser o sobre la naturaleza: nada existe; pero si algo existe, para el hombre es incognoscible (ágnoston), inaprehensible (akatálepton); aun si fuera cognoscible, aprehensible,

\footnotetext{
${ }^{24}$ Romilly 1971: 80, encuentra en el Sobre la verdad de Antifonte un relativismo cercano al de Protágoras.
}

Araucaria. Revista Iberoamericana de Filosofia, Politica, Humanidades y Relaciones Internacionales, año $22, \mathrm{n}^{\circ} 44$. Segundo semestre de 2020. Pp. 249-270. ISSN 1575-6823 e-ISSN 2340-2199 https://dx.doi.org/10.12795/araucaria.2020.i44.11 
es incomunicable e inexplicable (anéxoiston kaì anerméneuton, o ou delotón) a otros $^{25}$. A partir de esto Gorgias deduce que no se puede formular criterio útil de verdad, de lo cual se sigue que nada existe en el sentido de que no hay adecuación entre el intelecto y el ser de las cosas que permita arribar a la alétheia. Esta es la conclusión de Sexto Empírico (Contra los matemáticos, 7.87 = DK 82 B 3): "Tales son entonces las aporías desarrolladas por Gorgias: el criterio de la verdad (tò tês aletheías kritérion) se desvanece en cuanto depende de ellas. Porque no puede haber ningún criterio de aquello que no es, ni puede ser conocido, ni está en su naturaleza ser comunicado a los demás". Así, en la relación con los demás no se comunican las cosas sensibles sino la palabra, cuya realidad es de un orden distinto de ese supuesto real existente: el lógos no es lo real, pero es a través suyo que se comunica.

Por consiguiente, el hombre no tiene modo de escapar del discurso y sus constricciones. Las tres tesis de Gorgias sobre el no-ser adquieren su formulación más relevante en el último postulado, que dice que si algo existe y puede ser aprehendido no puede sin embargo ser comunicado a los demás (Sexto Empírico, Contra los matemáticos, 7.65); esto es lo que realmente interesa. Es en este plano donde el sofista postula la singularidad del lenguaje: su carácter social; la comunicabilidad que hace posible que haya un prójimo se erige a través suyo en una inmanencia respecto de la cual es menester ponderar incluso el problema del ser. Y puesto que no existe un criterio de verdad que actúe como garantía de adecuación entre la palabra y el mundo, entonces es el propio lógos el que establece las condiciones comunitarias de existencia, al producir las conexiones entre testigos o prójimos, esto es, todos los hombres que participan de la virtud política por el hecho de compartir una convención basada en el parecer circunstancial de la pólis, delimitando así una comunidad, un "nosotros", un lazo social imaginario. De allí que para Gorgias el problema de la alétheia no se plantee en el plano del lógos, ya que la verdad como adecuación entre la palabra y el mundo sensible es para su concepción algo imposible.

Teniendo en mente los aspectos planteados por Gorgias volvamos ahora a Antifonte. El hombre aislado puede aprehender la verdad en cuanto a los preceptos naturales, pero no sabría comunicarla a los demás, pues esta interacción en sí misma supone la esfera pública de una comunidad donde no impera la verdad sino la opinión, como indica Antifonte: en privado, la naturaleza es, pero tal verdad ontológica no puede ser enunciada a otros; en público, en el plano del lógos y el nómos, la naturaleza no es y, por ende, tampoco la verdad es. La política requiere sostener la ficción de la situación:

\footnotetext{
${ }^{25}$ Sintetizo aquí las versiones de estas tesis ap. Sexto Empírico, Contra los matemáticos, 7.65 (cf. 7.84) = DK 82 B 3, y [Aristóteles], Sobre Meliso, Jenófanes y Gorgias, 979a-980b 21 = DK 82 B 3bis, que usan distintos verbos para expresar el carácter incognoscible e incomunicable del ser. Respecto de lo que sigue, cf. Gallego, 2019.
}

Araucaria. Revista Iberoamericana de Filosofia, Política, Humanidades y Relaciones Internacionales, año $22, \mathrm{n}^{\circ} 44$. Segundo semestre de 2020. Pp. 249-270. ISSN 1575-6823 e-ISSN 2340-2199 https://dx.doi.org/10.12795/araucaria.2020.i44.11 
ser ciudadano entraña vivir en la hipocresía, enunciar solo lo que permite ser ciudadano, decir que se es justo e inscribirse en la virtud política. Protágoras, Gorgias y Antifonte no dicen otra cosa que esto: el lazo social imaginario es una ficción comunitaria que opera en el terreno de la opinión a partir de lo verosímil (cf. Cassin 1995: 171).

A un tiempo, la consistencia circunstancial de la política se organiza en sí misma como convención, y como su trama es discursiva es posible afirmar que funciona como lazo social imaginario. Su operatoria implica la ficción, terreno no de la verdad sino de lo verosímil, campo de fricción entre fuerzas que pueden reclamar con igual derecho la "verdad", pero que al hacerlo así muestran que no se está en el plano de la alétheia sino en el de la dóxa. Si la distinción entre ley y naturaleza se enuncia desde el discurso, si este por sí mismo hace ser por el solo hecho de enunciar, si la distinción aludida es entonces efecto de lógos, ¿puede algo que ha sido arrojado afuera del mundo de convenciones reaparecer en este? ¿Puede lo natural presentarse en lo político? ¿Puede el secreto de lo privado presentarse en público? Evocábamos antes que Protágoras excluía a todo aquel que decía la verdad, pero no era capaz de sostener la ficción de verdad sobre la que se fundaba la situación: era o un loco o un salvaje. Veamos qué dice Antifonte.

Tras distinguir entre ley y naturaleza y considerar lo que ocurre si se transgrede una u otra, el sofista argumenta que "la mayor parte de las cosas justas según la ley está en conflicto con la naturaleza”. El corolario extraído por Antifonte señala que "lo útil, tal como está fijado por la ley, es una cadena impuesta a la naturaleza; pero lo útil que la naturaleza fija es, en cambio, libre" (Sobre la verdad, fr. 1 A, col. II y IV). La libertad de acuerdo con la utilidad natural se contrapone a las ataduras de la ley, que imponen a los hombres unos fines que los apartan de aquellos que son más próximos y afines a la naturaleza (col. III). No se trata de una simple contraposición entre lo positivo y lo negativo de un orden u otro, porque la naturaleza es más bien amoral y no necesariamente inmoral (cf. Lévy 1976: 102). Ahora bien, teniendo en cuenta que en el argumento de Antifonte la distinción entre ley y naturaleza se hace desde el lógos y la ley es siempre primera y solo en un segundo momento se enuncia la naturaleza como tal -como un campo externo pero internalizado por la política-, hablar entonces de obedecer en público las leyes de la ciudad y en privado las de la naturaleza implica proyectar lo prescriptivo, que es del plano de lo contingente y convencional, sobre lo necesario en tanto que estado natural (col. I). La naturaleza, indica Cassin (1995: 189-190), imita a la ley y se presenta a la vez como el modelo de perfección del que la política solo es una distorsión: Antifonte no es sencillamente un naturalista que desprecia la ley en favor del placer de hacer lo que se quiera (col. IV-VI) ${ }^{26}$.

${ }^{26}$ Cf. Antifonte, DK 87 B 58 = Estobeo, Florilegio, 3.20.66; al respecto, Farrar 1988: 118-119; ver 
Es necesario avanzar otro paso más sobre las reflexiones del sofista para concretar la respuesta a las cuestiones que se dejaron planteadas. De acuerdo con otro fragmento del Sobre la verdad (fr. 1 B, col. II), el problema de la igualdad, un asunto básico para la política de la pólis, se debería replantear según una valoración diferente de las nociones de nómos y phýsis:

En esto nos comportamos como bárbaros (bebarbarómetha) unos con otros, ya que por naturaleza ( $p$ hýsei) todos hemos nacido para ser semejantes en todo, tanto griegos como bárbaros. Y es posible constatar que las cosas que son por naturaleza son necesarias a todos los hombres... Ninguno de nosotros ha sido distinguido, desde el comienzo, ni como griego ni como bárbaro.

Las prácticas y concepciones habituales que este pasaje critica hacen hincapié en la desigualdad entre griegos y bárbaros, lo cual supone una decidida condena a esta tradicional distinción. No obstante, los dichos previos a esta cita, hasta donde se puede leer y según las restituciones adoptadas, parecen apuntar a otras diferencias incluso más fuertes dentro de la ciudad: entre nobles y no nobles, entre ciudadanos y no ciudadanos. En el dominio político, propone Lévy (1976: 103), este tipo de pensamiento es verdaderamente revolucionario, ya que en nombre de la naturaleza y la utilidad incita a rechazar la ley y la tradición. Obsérvese que, si bien Antifonte habla de igualdad natural entre griegos y bárbaros, no obstante, esta idea resulta apropiada para dar cuenta de un comportamiento que hace particular hincapié en la desigualdad y, por ende, en la inferioridad. Es aquí donde vemos producirse una inversión de los términos: si participar en la política (politeúetaí tis) supone no transgredir las leyes de la ciudad a la que se pertenece, si la práctica política se funda sobre la diferencia y exclusión del que por naturaleza es igual (el no noble, el no ciudadano, el bárbaro), entonces, es en el ámbito de la vida pública y las leyes de la ciudad donde los hombres, obedeciendo frente a sus conciudadanos lo que las leyes ordenan, se comportan como bárbaros (bebarbarómetha), ya que establecen diferencias políticas y legales respecto a otros que son naturalmente semejantes a ellos. Así, se instituye en el marco de la política el destierro de los que son iguales por naturaleza, pero diferentes según la ley. Por consiguiente, las mismas leyes por las que un hombre se hace ciudadano de la pólis lo convierten paralelamente en bárbaro en relación con los no ciudadanos, a los que considerará como diferentes y, en el límite, como inferiores. En Antifonte hay, pues, una articulación lógica entre la naturaleza y la ley que entronca con el hecho de ser ciudadano de una ciudad y volverse bárbaro allí mismo. Como concluye Cassin (1995: 188) en su análisis de este problema:

también Antifonte, Sobre la verdad, fr. 2, col. I-II = DK 87 B 44; Romilly 1971: 87.

Araucaria. Revista Iberoamericana de Filosofia, Politica, Humanidades y Relaciones Internacionales, año $22, \mathrm{n}^{\circ} 44$. Segundo semestre de 2020. Pp. 249-270. ISSN 1575-6823 e-ISSN 2340-2199 https://dx.doi.org/10.12795/araucaria.2020.i44.11 


\begin{abstract}
Si se parte de "ciudadanizar", la naturaleza es lo que escapa a lo político en lo político mismo. Pero ella constituye al mismo tiempo una legislación imparable, algo así como el modelo mismo de la ley: nada la transgrede sin ser castigado. Si se parte de "barbarizar", la naturaleza es descalificada como fundamento de las diferencias, bárbaro es el que cree en una diferencia natural entre griego y bárbaro, griego es el que se relaciona con la ley no como idiosincrasia sino como universal. Pero es aún... la naturaleza la que constituye el modelo de esta universalidad.
\end{abstract}

Existe por ende una división entre la legalidad de la naturaleza y la de la ley, entre la ley natural del hombre y la ley política del ciudadano, que conduce a que la única forma posible de representar la universalidad legal sea atenerse a esa necesidad natural que no convierte en bárbaro. Antifonte llega así a proponer que la adecuación de los actos con la verdad solo se consigue respetando la naturaleza; pero esta, a la que se le concibe una legalidad superior a la de la ley de la ciudad, tiene por modelo justamente a esta última. La deducción de Cassin (1995: 190) es elocuente: el procedimiento empleado por Antifonte implica una torsión entre naturaleza y ley en el núcleo mismo de la ley, de lo cual es todo un síntoma la posición de la naturaleza en el interior de la ley misma. Es posible ceñirse a la visión de Lévy, que ve una concepción verdaderamente revolucionaria que rechaza la ley en nombre de la naturaleza, o a la de Cassin, que percibe a la naturaleza como una torsión sintomática en el seno mismo de la ley; de un modo u otro, se está ante algo que le hace obstáculo a la ley en tanto que en ella se incluye.

¿Qué tipo de obstáculo es el que el enunciado de la igualdad natural viene a producir en la situación política? Para Antifonte, griegos y bárbaros son naturalmente iguales; la diferencia solo existe en el plano de la ley, pues se actúa según justicia cuando no se transgrede la ley de la pólis en la cual alguien se "politiza" (politeúetai tis); así, hay desigualdades por la ley, pero no las hay por naturaleza. Ahora bien, si la naturaleza no es parte de lo público sino el secreto de lo privado y en el terreno de la ley y la política se debe actuar según lo que se adecua a estas y solo en el plano de lo privado se debe obedecer a la naturaleza, entonces, asumir y decir la verdad respecto de la igualdad natural de griegos y bárbaros, como lo hace Antifonte, no constituye para la situación política un enunciado capaz de producir una "revolución" sino que, en rigor, lleva a la disolución de los fundamentos de la pólis. Se trata de una interdicción estructural cuya aparición en el campo de la convención política la desestructuraría: la naturaleza no es del orden de lo político, sino que es su límite, más allá del cual la política deja de existir.

Si la naturaleza no puede advenir en la política es a causa de que, como Gorgias proponía, la naturaleza es el no-ser, en el sentido de que el lógos no puede jamás comunicarla. De igual modo podemos argumentar para Antifonte, 
pues en su discurso la naturaleza es la verdad que no puede ser dicha en público, ya que implicaría en presencia de testigos no respetar las leyes por las que se adquiere la ciudadanía. La política es un asunto de discurso y opinión, no funciona según un criterio ontológico de verdad. La tesis protagorea de que la virtud política es enseñable, puesto que todos participan del arte político, adquiere así una mayor precisión: "todos" significa el conjunto de los ciudadanos de acuerdo con la ley de la ciudad de la que se forma parte. El mérito de Antifonte es haber sido consecuente al extraer las conclusiones radicales que se derivan de la tesis relativista de toda convención política ${ }^{27}$.

\section{A modo de conclusión: entre la palabra y la ley}

A lo largo del recorrido realizado, se ha discurrido sobre dos problemas medulares del pensamiento sofístico: la palabra y la ley. Desde ambos ejes, se ha tratado de bosquejar ciertos fragmentos de un discurso sofístico sobre la verdad, ya no como adecuación del intelecto al mundo exterior, en posición de ser o realidad, sino como construcción discursiva que supone una serie de condiciones y procedimientos de producción. La verdad así comprendida no emerge como una esencia pura, absoluta y sustancial, sino como consecuencia de un encuentro de fuerzas múltiples, lo cual conlleva una verdad sometida a divisiones, tensiones, dispersiones, efecto de discurso donde el debate y la publicidad constituyen sus procedimientos de producción insoslayables. La verdad así fabricada es un resultado eminentemente práctico de, e inmanente a, una situación urdida por una multiplicidad de posiciones cuya coexistencia es posible justamente mediante la palabra y la ley, operadores que instituyen el lazo social imaginario como comunidad de lengua y como comunidad de norma. Que el decir haga ser o que la norma pueda ser cambiada hablan del mismo asunto: la práctica política en tanto que poder instituyente conformado bajo las condiciones de una convención a la vez discursiva y legal. En tales circunstancias, el régimen de verdad ya no se asocia a la transparencia de una trascendencia inmutable, el lugar de la Verdad con mayúscula ${ }^{28}$, sino a la ambigüedad de las palabras persuasivas, productoras de opiniones y verosimilitudes, de artificios, estratagemas y ficciones, modo de fabricación de la verdad política bajo las reglas de juego de las prácticas retóricas de la pólis.

${ }_{27}$ Sobre el relativismo protagoreo, ver Cole 1972; Romilly 1997: 106-109; Zilioli 2007: 113-140; 2013; Giorgini 2010; Rowett 2013.

${ }_{28}$ La Verdad con mayúscula remite aquí a esos modos de producción de verdad que ha estudiado Detienne 1981: 21-85, bajo las especies de la palabra mágico-religiosa en contraposición con la palabra-diálogo. Un análisis filosófico de esos lugares de la Verdad con mayúscula se puede leer en Balibar 1995: 39-70. 


\section{Referencias bibliográficas:}

Avery 1982: H.C. Avery, “One Antiphon or Two?”, Hermes, 110 (1982), pp. 145-158.

Balibar 1995: E. Balibar, Nombres y lugares de la verdad [1994], tr. P. Mahler (Buenos Aires, 1995).

Barthes 1982: R. Barthes, Fragmentos de un discurso amoroso [1977], tr. E. Molina (México, 1982).

Bartlett 2016: R.C. Bartlett, Sophistry and Political Philosophy: Protagoras' Challenge to Socrates (Chicago, 2016).

Beresford 2013: A. Beresford, "Fangs, Feathers, and Fairness: Protagoras on the Origins of Right and Wrong", en J. van Ophuijsen, M. van Raalte y P. Stork (eds.), Protagoras of Abdera: The Man, his Measure (Leiden, 2013), pp. 139-162.

Bertrand 1999: J.-M. Bertrand, De l'écriture à l'oralité. Lectures des Lois de Platon (Paris, 1999).

Bignone 1919a: E. Bignone, "Antifonte oratore e Antifonte sofista", Rendiconti: Reale Istituto Lombardo, 52 (1919), pp. 564-578.

Bignone 1919b: E. Bignone, "Studi stilistici su Antifonte oratore e Antifonte sofista”, Rendiconti: Reale Istituto Lombardo, 52 (1919), pp. 755-776.

Bignone 1974: E. Bignone, Antifonte oratore e Antifonte sofista (Urbino, 1974). Bieda 2008: E. Bieda, "Antifonte sofista: un utilitarismo naturalista”, Méthexis, 21 (2008), pp. 23-42.

Bonazzi 2004a: M. Bonazzi, "Antifonte il retore, il sofista, l'ateniese: in margine a due recenti pubblicazioni", Rivista di Storia della Filosofia, 3 (2004), pp. 769-775.

Bonazzi 2004b: M. Bonazzi, "Atene, i sofisti e la democrazia: Protagora e i suoi critici”, Il Pensiero Politico, 37 (2004), pp. 333-359.

Cairns 1993: D.L. Cairns, Aidōs: The Psychology and Ethics of Honour and Shame in Ancient Greek Literature (Oxford, 1993).

Cassin 1995: B. Cassin, L'effet sophistique (Paris, 1995).

Chialva et al. 2013: I.S. Chialva et alii, Gorgias. Encomio a Helena, estudio preliminar, texto, traducción y notas (Santa Fe, 2013).

Cole 1972: T. Cole, "The Relativism of Protagoras", Yale Classical Studies, 22 (1972), pp. 19-45.

Cole 1991: T. Cole, The Origins of Rhetoric in Ancient Greece (Baltimore, 1991).

Corrales Cordón 2010: F.D. Corrales Cordón, “Consideraciones sobre las tesis igualitaristas del Sobre la verdad de Antifonte el sofista", Astrolabio: Revista Internacional de Filosofía, 11 (2010), pp. 134-142. 
Desbordes 1996: F. Desbordes, La rhétorique antique. L'art de persuader (Paris, 1996).

Detienne 1981: M. Detienne, Los maestros de verdad en la Grecia arcaica [1967], tr. J.J. Herrera (Madrid, 1981).

Donda, Reynoso y Rufinetti 1994: C. Donda, R. Reynoso y E. Rufinetti, "Antifonte: la ronda dialéctica de physis y nomos", Nombres: Revista de Filosofía, 5 (1994), pp. 53-62.

Enos 1992: R.L. Enos, "Why Gorgias of Leontini Traveled to Athens: A Study of Recent Epigraphical Evidence”, Rhetoric Review, 11 (1992), pp. 1-15.

Farrar 1988: C. Farrar, The Origins of Democratic Thinking: The Invention of Politics in Classical Athens (Cambridge, 1988).

Gagarin 1990: M. Gagarin, "The Ancient Tradition on the Identity of Antiphon", Greek, Roman and Byzantine Studies, 31 (1990), pp. 27-44.

Gagarin 1994: M. Gagarin, "Probability and Persuasion: Plato and Early Greek Rhetoric", en I. Worthington (ed.), Persuasion: Greek Rhetoric in Action (London, 1994), pp. 46-68.

Gagarin 2002: M. Gagarin, Antiphon the Athenian: Oratory, Law, and Justice in the Age of the Sophists (Austin, 2002).

Gallego 2000: J. Gallego, "Protágoras y la invención humana de la política: las condiciones del pacto social en la Atenas democrática”, Argos, 14 (2000), pp. 85-112.

Gallego 2003: J. Gallego, La democracia en tiempos de tragedia. Asamblea ateniense y subjetividad política (Buenos Aires, 2003).

Gallego 2016: J. Gallego, "La politique, une invention humaine ou divine? La pensée de Protagoras et le regard platonicien”, Dacia, 60 (2016), pp. 111-120.

Gallego 2018a: J. Gallego, "Filolaconismo y política oligárquica en Atenas a finales del siglo V a.C.”, Habis, 49 (2018), pp. 43-63.

Gallego 2018b: J. Gallego, La anarquía de la democracia. Asamblea ateniense y subjetivación del pueblo (Buenos Aires, 2018).

Gallego, 2019: J. Gallego, "Ser o no ser, esa es la cuestión: el lógos según Gorgias”, en M.C. Colombani, G. Fernández Parmo y J.M. Gerardi (eds.), Estudios de Filosofía, Historia y Literatura de la Antigüedad Clásica. Contribuciones en homenaje al Profesor Francisco Olivieri (Mar del Plata, 2019, pp. 33-48).

Gernet 1923: L. Gernet, Antiphon. Discours, introducción, texto, traducción y notas (Paris, 1923).

Giorgini 2010: G. Giorgini, “Does Democracy Necessarily Rest on Relativism? The Origins of the Debate: Protagoras and Plato", Rivista Elettronica della Società Italiana di Filosofia Politica (17 dicembre 2010), http://eprints. sifp.it/262/. 
Gomperz 1951: T. Gomperz, Pensadores griegos. Historia de la Filosofía en la Antigüedad [1896], tr. C.G. Körner (Buenos Aires, 1951), tomo I.

Grimaldi 1996: W.M.A. Grimaldi, "How Do We Get from Corax-Tisias to Plato-Aristotle in Greek Rhetorical Theory?", en C.L. Johnstone (ed.), Theory, Text, Context: Issues in Greek Rhetoric and Oratory (Albany, 1996), pp. 19-43.

Guthrie 1971: W.K.C. Guthrie, The Sophists (Cambridge, 1971).

Kennedy 1994: G.A. Kennedy, A New History of Classical Rhetoric (Princeton, 1994).

Lesky 1968: A. Lesky, Historia de la literatura griega [1963²], tr. J.M. Díaz Regañón y B. Romero (Madrid, 1968).

Lévy 1976: E. Lévy, Athènes devant la défaite de 404. Histoire d'une crise idéologique (Paris, 1976).

Levystone 2014: D. Levystone, "Antiphon: indifférence de la nature, misère des lois humaines", Phoenix, 68 (2014), pp. 258-290.

López Eire 1994: A. López Eire, "Literatura y vida pública: orígenes de la retórica”, en A. López Eire y C. Schrader (eds.), Los orígenes de la oratoria y la historiografía en la Grecia clásica (Zaragoza, 1994), pp. 9-73.

Luria 1963: S. Luria, “Antiphon der Sophist”, Eos, 53 (1963), pp. 63-67.

Manuwald 2013: B. Manuwald, 2013. “Protagoras' Myth in Plato's Protagoras:

Fiction or Testimony?", en J. van Ophuijsen, M. van Raalte y P. Stork (eds.), Protagoras of Abdera: The Man, his Measure (Leiden, 2013), pp. 163-177.

Mondolfo 1955: R. Mondolfo, La comprensión del sujeto humano en la cultura antigua (Buenos Aires, 1955).

Monoson 2000: S.S. Monoson, Plato's Democratic Entanglements: Athenian Politics and the Practice of Philosophy (Princeton, 2000).

Morrison 1961: J.S. Morrison, "Antiphon", Proceedings of the Cambridge Philological Society, 187 (1961), pp. 49-58.

Nestle 1961: W. Nestle, Historia del espíritu griego desde Homero hasta Luciano [1944], tr. M. Sacristán (Madrid, 1961).

Ostwald 1986: M. Ostwald, From Popular Sovereignty to the Sovereignty of Law: Law, Society, and Politics in Fifth-Century Athens (Berkeley, 1986).

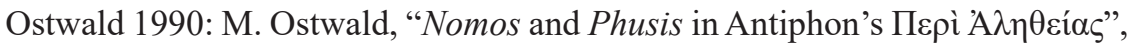
en M. Griffith y D.J. Mastronarde (eds.), Cabinet of the Muses: Essays on Classical and Comparative Literature in Honor of Thomas G. Rosenmeyer (Berkeley, 1990), pp. 293-306.

Palerm 1996: V.R. Palerm, “Antifonte de Ramnunte y la 'cuestión antifontea'. Actualización crítica e interpretación unitaria”, Habis, 27 (1996), pp. 2339. 
Pendrick 1987: G.J. Pendrick, "Once Again Antiphon the Sophist and Antiphon of Rhamnus", Hermes, 115 (1987), pp. 47-60.

Pendrick 2002: G.J. Pendrick, Antiphon the Sophist: The Fragments, introducción, edición, traducción y comentario (Cambridge, 2002).

Plácido 1973: D. Plácido, "El pensamiento de Protágoras y la Atenas de Pericles", Hispania Antiqua, 3 (1973), pp. 29-68.

Plácido 1989: D. Plácido, "Antifonte", en M.J. Hidalgo de la Vega (ed.), Homenaje a Marcelo Vigil Pascual. La Historia en el contexto de las Ciencias Humanas y Sociales (Salamanca, 1989), pp. 29-36.

Plácido 1997: D. Plácido, "La ciudad se define: Sócrates y los sofistas", en J. Alvar y J.M. Blázquez (eds.), Héroes y antihéroes en la Antigüedad clásica (Madrid, 1997), pp. 69-77.

Romilly 1971: J. de Romilly, La loi dans la pensée grecque des origines à Aristote (Paris, 1971).

Romilly 1997: J. de Romilly, Los grandes sofistas en la Atenas de Pericles [1988], tr. P. Giralt Gorina (Barcelona, 1997).

Rowett 2013: C. Rowett, "Relativism in Plato's Protagoras", en V. Harte y M. Lane (eds.), Politeia in Greek and Roman Philosophy (Cambridge, 2013), pp. 191-211.

Saxonhouse 2006: A. Saxonhouse, Free Speech and Democracy in Ancient Athens (Cambridge, 2006).

Schiappa 1999: E. Schiappa, The Beginnings of Rhetorical Theory in Classical Greece (New Haven, 1999).

Solana Dueso 2000: J. Solana Dueso, El camino del ágora. Filosofía política de Protágoras de Abdera (Zaragoza, 2000).

Sørensen 2016: A.D. Sørensen, Plato on Democracy and Political Technē (Leiden, 2016).

Tortora 1985: G. Tortora, "Il senso del kairós in Gorgia”, Siculorum Gymnasium, 38 (1985), pp. 537-364.

Untersteiner 1949: M. Untersteiner, I sofisti (Torino, 1949).

Williams 1931: B.H.G. Williams, "The Political Mission of Gorgias to Athens in 427 B.C.", Classical Quarterly, 25 (1931), pp. 52-56.

Yunis 1998: H. Yunis, "The Constraints of Democracy and the Rise of the Art of Rhetoric", en D. Boedeker y K.A. Raaflaub, (eds.), Democracy, Empire, and the Arts in Fifth-Century Athens (Cambridge MA, 1998), pp. 223-240.

Zilioli 2007: U. Zilioli, Protagoras and the Challenge of Relativism: Plato's Subtlest Enemy (Aldershot. 2007).

Zilioli 2013: U. Zilioli, "Protagoras through Plato and Aristotle", en J. van Ophuijsen, M. van Raalte y P. Stork (eds.), Protagoras of Abdera: The Man, his Measure (Leiden, 2013), pp. 233-258. 